\title{
In-situ TEM observation of $\mathrm{Ni} / \mathrm{Al}_{2} \mathrm{O} 3$ catalysts for dry reforming of methane
}

\author{
Ayako Hashimoto ${ }^{1}$ and Yutian $\operatorname{Han}^{2}$ \\ ${ }^{1}$ National Institute for Materials Science, Tsukuba, Japan, ${ }^{2}$ University of Tsukuba, Tsukuba, Japan
}

Ni-based catalysts are useful for dry reforming of methane (DRM, CH4 + $\mathrm{CO} 2$ à $2 \mathrm{H} 2+2 \mathrm{CO})$ owing to their high catalytic activities and lower cost compared with noble metals. However, these catalysts have some disadvantages, such as a high activity temperature and high possibility of deactivation. During a DRM reaction, Nibased catalysts are easily deactivated via carbon formation, a process that is referred to as coking, generated from side reactions. Therefore, retaining their activities without using water and steam for inhibiting carbon formation would be challenging in actual applications. Although several researchers have reported improvements in catalytic activities and stabilities [1], coking and catalyst deactivation have not been completely understood and overcome yet. In this work, structural and chemical changes of Ni nanoparticles during the DRM process were elucidated using in-situ transmission electron microscopy (TEM) with electron energy-loss spectroscopy (EELS) analysis.

Two Ni/Al2O3 catalyst powders with different mass ratios (5 wt $\%$ and $10 \mathrm{wt} \%$ ) were prepared through the impregnation method, as shown in Fig. 1(a). Firstly, Ni(NO3)2.6H2O and $\mathrm{Al} 2 \mathrm{O} 3$ were dissolved into ethanol. After $8 \mathrm{~h}$ of stirring, the remaining ethanol was evaporated at $80{ }^{\circ} \mathrm{C}$. Then, the powders were heated in $5 \% \mathrm{H} 2+95 \% \mathrm{Ar}$ at $600{ }^{\circ} \mathrm{C}$ for $6 \mathrm{~h}$ to refine the particle size and reduce oxidized $\mathrm{Ni}$. In this study, $5 \mathrm{wt} \%$ and $10 \mathrm{wt} \% \mathrm{Ni} / \mathrm{Al} 2 \mathrm{O} 3 \mathrm{were}$ imaged in gas conditions at approximately 0.3 and $13 \mathrm{~Pa}$ pressure, respectively. To avoid carbon contamination, each TEM observation started at a temperature of $150^{\circ} \mathrm{C}$ before introducing the gases, and the electron dose through the specimen was kept lower than $10 \mathrm{pA} / \mathrm{cm} 2$. The specimens were then gradually heated to $350{ }^{\circ} \mathrm{C}$ and $450{ }^{\circ} \mathrm{C}$ to react with $\mathrm{CH} 4$ or DRM (a mixture gas containing 50\% CO2 and 50\% CH4) gases.

For in-situ observations, our previously developed specific gas heating specimen holder was used [2]. A Sibased heater chip (E-chip, Protochips, USA) with Ni/Al2O3 powder was arranged in a specimen room at the tip of the specimen holder and connected to a heater controller outside of the TEM column (JEM-ARM200F, JEOL, Japan). The chip was then sandwiched between two orifice plates to create a differential pumping effect, which enabled a higher environmental pressure in the specimen room without breaking the column vacuum. The pressure in the specimen room was monitored in the form of a voltage value measured via a multimeter using a tiny vacuum gauge near the $\mathrm{Ni} / \mathrm{Al} 2 \mathrm{O} 3$ powder.

Under $\mathrm{CH} 4$ conditions, the Ni nanoparticles exhibited significant changes in their positions and shapes during in-situ observations. Furthermore, some graphitic structures were observed above $450{ }^{\circ} \mathrm{C}$ on the surface of the $\mathrm{Ni}$ particles under the both pressure conditions $(0.3$ and $13 \mathrm{~Pa})$, as shown in Fig.1(b). This indicates that carbon can form on the Ni nanoparticles by decomposing the introduced $\mathrm{CH} 4$ gas. In addition, a few small Ni particles were formed from the larger $10 \mathrm{wt} \% \mathrm{Ni} / \mathrm{Al} 2 \mathrm{O} 3$ particles. Pure $\mathrm{Al}$ was also detected near a $\mathrm{NiO}$ particle, which is formed via decomposition of the $\mathrm{Al} 2 \mathrm{O} 3$ support.

On the other hand, under DRM conditions, the graphitic structure could not be observed, but several Ni3Clike structures were observed. The coking phenomena were not obvious, thus demonstrating that the presence of $\mathrm{CO} 2$ in the DRM gas inhibits coking. Some types of Ni-Al compounds were also found, presumably due to the interaction of the Ni nanoparticles with the Al2O3 support.

The Ni valence changes during TEM observations were evaluated through the white line ratio (WLR) from the in-situ EELS analysis. The valence states increased overall, showing that Ni nanoparticles under $\mathrm{CH} 4$ gas conditions were oxidized because of oxygen from the $\mathrm{Al} 2 \mathrm{O} 3$ support, whereas they were oxidized mainly because 
of the $\mathrm{CO} 2$ gas under the DRM condition. However, some Ni nanoparticles still remained, which might be attributed to the reduction of the formed $\mathrm{NiO}$ particles and the interaction with the support. Thus, under both conditions, oxidation and reaction of the Ni nanoparticles simultaneously occurred during the reaction processes.
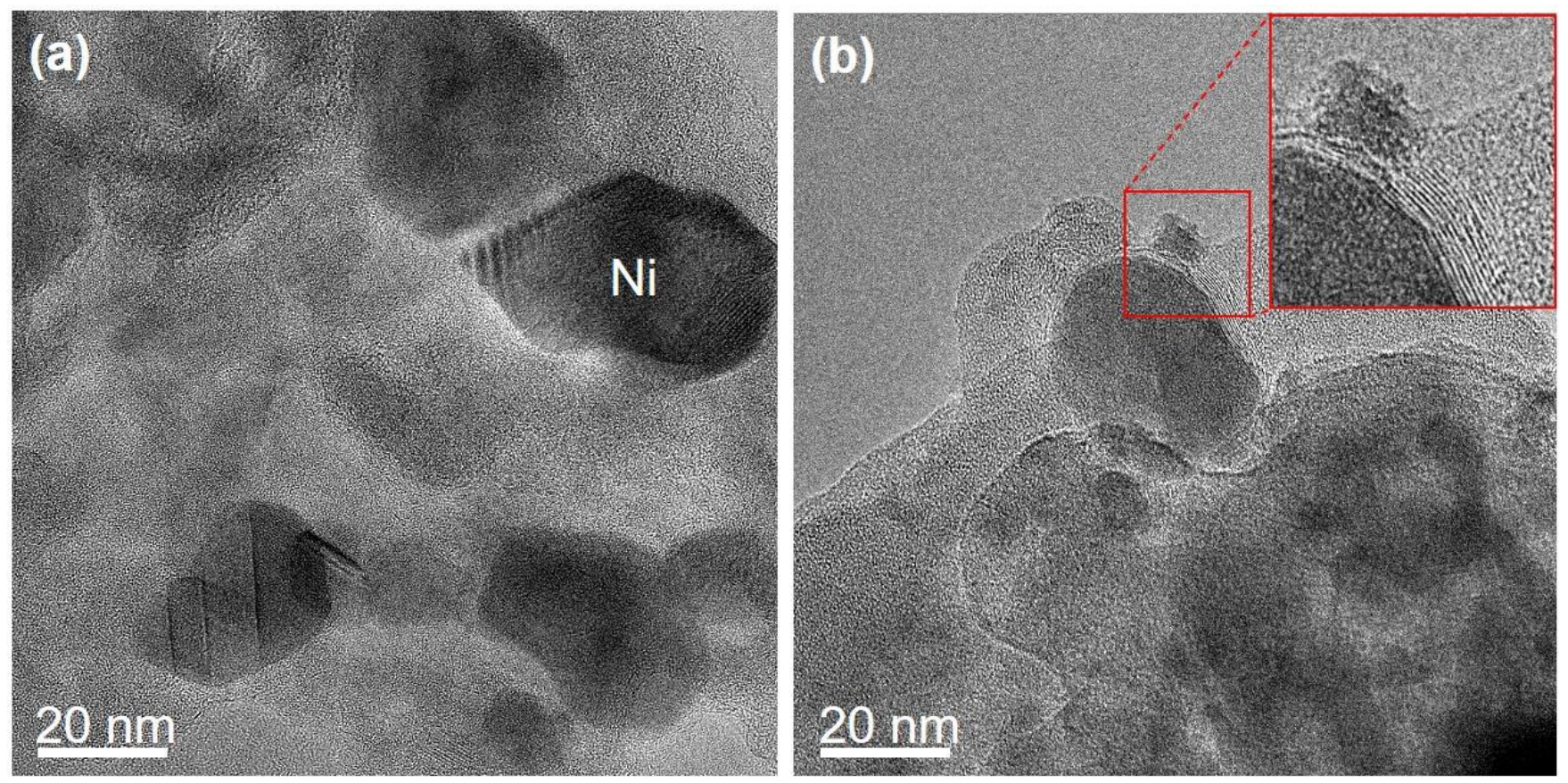

Figure 1. TEM images of $10 \mathrm{wt} \% \mathrm{Ni} / \mathrm{Al} 2 \mathrm{O} 3$ catalysts (a) before gas introduction at $150{ }^{\circ} \mathrm{C}$, and (b) in pure $\mathrm{CH} 4$ gas at $450{ }^{\circ} \mathrm{C}$.

\section{References}

[1]A. Guerrero-Ruiz et al, Applied Catalysis A General 170 (1998) 177.

[2] A, Hashimoto et al, AMTC Letters 6 (2019) 108. 